\title{
Introducing Efficient AODV Routing Protocol for MANET
}

\author{
Anumeha \\ M.Tech., CSE \\ Galgotia College of Engineering \&Technology , \\ Greater Noida
}

\author{
Bhawna Mallick, PhD \\ Dean Academic \& HOD \\ Galgotia College of Engineering \& Technology, \\ Greater Noida
}

\begin{abstract}
An ad-hoc network is a multi-hop wireless network system where all the nodes cooperatively maintain the network connectivity without any centralized infrastructure. If these nodes in the network cannot remain in their same positions means position various dynamically, that is called a mobile ad-hoc network (MANET) system. Efficient protocols are used here to forward data packets with very low packet loss.In this paper, an adaptive routing algorithm is proposed in MANET using modified AODV by calculating the loads on different routes using given parameters like aggregate interface queue length and nodes remaining energy. An Adhoc on Demand Distance Vector Protocol (AODV) for routing is one among the effective Reactive Routing Protocols in MANET. The objective of this paper is to basically enhance the AODV network performance, when frequent link failures in network due to mobility of the nodes. The simulations and performance analysis are carried out to evaluate the network performance using Network Simulator tool (NS-2), based on the quantitative metrics packet delivery ratio and average end to end delay. The achieved simulated result helps to understand the precise behaviour of the AODV in the distributed network environment. This paper proposed a new protocol E-AODV (Enhanced AODV) which is a modified AODV with Enhanced packet delivery ratios and minimized end to end packet delay.
\end{abstract}

\section{General Terms}

Enhancing the performance of AODV Routing Protocol and Compare it with other routing protocols.

\section{Keywords}

Ad hoc Network, AODV, Enhanced AODV, Packet delivery Ratio, End to End Delay, Throughput

\section{INTRODUCTION}

An Ad hoc Network (MANET) [1, 2] is a wireless network for collection of independent mobile nodes that communicate to each other via radio waves. The mobile nodes, in radio range of each other, can communicate directly, whereas others need the maintenance of intermediate nodes to route the packets. These networks are fully distributed, and can work at any place without any help of specific infrastructure. This feature makes these networks robust and highly flexible. Dynamic change in the MANET topology [3, 4] makes routing process as a challenging goal or task, as the existing route or path is rendered inefficient, inaccurate and infeasible. The major issues for MANETs are routing, security, medium access control (MAC) and quality of service provisioning. This paper provides or addresses the routing related problem in access control and security. Routing in MANET basically means the imposed flow of data to destination from source with maximizing the network performance. The characteristics of these networks are summarized below:
- Neither centralized neither controller nor infrastructure.

- Dynamic Network topology.

- $\quad$ Frequent routing updates.

- $\quad$ Nodes play the role of hosts and routers as well.

- Intrinsic mutual trust.

- $\quad$ Some applications of MANETs :

- Disaster relief operations.

- Defence Development

- Urgent Business meetings.

- Mine site operations.

Network Simulator (NS-2) is an object oriented, event driven, network simulating tool. It is very much used by the researchers, professors and students. Basically, Simulation is the process of creating a model with its relative behaviour. There number of network simulating tools are available such as GloMoSim, OPNET, QualNet, NS-2 etc. But NS-2 is the most suitable among all the other. So many Routing protocols of MANET such as AODV, DSDV, DSR ares implemented using NS-2 and it's available as free open source software programs. In this paper, AODV protocol is considered and its network performance is enhanced by E-AODV.

\section{ROUTING PROTOCOL FOR MANET}

Routing is the process to send information from one host to another host. Routing means route packet to its destination using efficient path. Protocols are set of rules. Routing protocols are required where source needs to communicate to the destination.

\subsection{Reactive Routing Protocol}

Routes are searched to be found when there is a demand or need. Hence, it basically reduces the unnecessary routing overhead. Here, no need to search for and maintain the routes on which route request is being made. Reactive routing protocols are very useful and effective in the resource-limited environment. The approach is best suited when the network is static and the traffic is very light. For ex: DSR, AODV [ 15, 16 ].

\subsection{Proactive Routing Protocol}

All possible Routes to all destination nodes are maintained by sending several periodical control messages. There is unnecessary wastage of bandwidth for sending control packets. Proactive routing protocols suitable for smaller networks, as it needs to maintain the route information for every node's routing table. This generally causes more overhead leads to the consumption of more and more bandwidth. For ex: DSDV [10,11]

- Communication via wireless Network 


\subsection{Hybrid Routing Protocol}

An Ad Hoc network can use the hybrid routing protocols that have the advantages of both $\mathrm{p}$ reactive and proactive routing protocols to control overhead and balance the delay(in terms of controlling packages). The only difficulty of all hybrid routing protocols is the complexity to organize the network according to the network parameters. The most common disadvantage of hybrid routing protocols is that the nodes having high level topological information, prepares many routing details and information, which supports to more memory and power consumptions.

\section{AODV PROTOCOL}

An AODV protocol is a source initiated on-demand routing protocol. Every mobile node in network maintains a routing table that maintains the hop node information to next node for a route to destination node. When a source node desires to route a packet to a destination node, in this process it commonly uses the unique or specific route if a new route to the destination node is available in its maintained routing table. If it's not, it starts a route discovery process by simply broadcasting the Route Request (RREQ) message to its neighbours nodes, which is further broadcasted until it reaches an intermediate node with a new enough route to the destination node destination node itself or specified in the RREQ. Each and every intermediate node receiving the RREQ, makes as an entry in its routing table for node that forwarded the RREQ message, and also to the source node .The the intermediate node or destination node with a new enough route to the destination node, basically unicast the Route Response (RREP) message to its neighbouring node from which it received the RREQ request. An intermediate node makes an entry point for the neighbouring node from which it received the RREP message, and then forwards the RREP in the opposite direction. On getting or receiving the RREP information message, the source node every time updates its routing table with an entry for the destination node, and also the node from which it received the RREP message. Now the source node starts routing the data packets to the destination node through the neighbouring node that firstly responded with an RREP.

\section{AODV are:}

- $\quad$ Route Request Message (RREQ)

- $\quad$ Route Reply Message (RREP)

- $\quad$ Route Error Message (RERR)

- $\quad$ Route Reply Acknowledgment (RREP-ACK)

Message

\section{- HELLO Messages}

\subsection{Route Discovery}

When a source node is being considered as to send a message to any destination node, and it doesn't have any valid route to reach the destination, it initiates a path discovering process to address the other node. Initially it broadcasts a route request (RREQ) control packet to its neighbours, after that forward this request to their neighbours, and so on. This AODV protocol uses the sequence numbers for destination basically to ensure that all routes contain the latest route information. Each node prepares its self sequence number. During this forwarding process, the intermediate nodes of RREQ record the address of the neighbour from which the first copy of the broadcast packet is received in their route tables, by establishing a reverse path. Once the RREQ reaches the destination or an intermediate node with a fresh route, the destination node responds by unicasting the route reply (RREP) control packet back to its neighbour from which first it received the RREQ $[6,7]$.

\subsection{Route Maintenance}

A route discovering between a source node and corresponding destination node is maintained as long as needed by the source node. The destination node node moves, the node initiates Route Error (RERR) message to the affected its active neighbours or nodes. In a same manner, these nodes propagate the RERR to their predecessor nodes. When the source node is reached this procedure stops working. When the RERR is received by the source node, either it can stop sending the data or reinitiates the route discovery process by sending a new RREQ message if the route is required still $[9,10]$.

\section{PROPOSED METHODOLOGY}

This section described new methodology to show the difference between the AODV routing protocols and EAODV during the transmission with the following simple topology. Basically there are four nodes in this network; there is grid topology for this network and the method shown in Table-1. Sequentially, at the beginning of the transmission for nodes, the two pairs aren't interference with each other. After 10 s, Node 2 moves towards the path to Node 0 with the speed of $10 \mathrm{~m} / \mathrm{s}$. The distance between Node 0 and Node 2 gets smaller and smaller, and at time $15 \mathrm{~s}$, After this these two nodes get start to be in each other's range area of carrier sensing, which means that these two nodes start sharing the same channel. The max bandwidth of this channel is around 3.64 Mbps. In AODV, where there are no QoS requirements, when Node 2 comes in the interference range of Node 0 , these traffics are kept on and some packets have lost during the transmission, on other hand, in E-AODV, the QoS is fully ensured. When the expected data rate cannot be compromised any more, traffic of Node 2 is stopped at once. Behalf of this case, we can see that the E-AODV achieves the benefits of ensuring the QoS not only at route discovery stage, but also during the transmission process $[8,9]$.

\section{[Route discovery process]}

Source node $N S$ wants to find a path to destination node $N d$. Suppose that $z$ is the number of mobile nodes and $N$ is the set of mobile nodes, i.e., $N=\{N 1, N 2, \ldots, N z\}$, where $N s, N i$, $N d N, 1 s, d, i z$ and $s d$. We assume that node $N i$ is an intermediate node that receives the RREQ packet.

If (node $N i$ is the destination node $N d$ )

\{

1. Destination node $N d$ adds its remaining energy (RE), hop count (HC) and aggregate interface queue length (AIQL) to the RREP packet.

2. Destination node $N d$ forwards the RREP packet towards the source node along the path through which the RREQ packet had arrived at the destination node.

3. Destination node responses to each of the RREQ by sending Route Reply for each RREQ packet arriving at the destination node through different routes.

4. The intermediate node adds up its remaining energy and queue size with the route energy and aggregate interface queue length field in the RREP 
respectively and forwards the route reply towards the source node

5. Ns.

\}

Else

Node Ni forwards the RREQ packet to the neighboring node.

\section{B. Route Selection}

After receiving all the RREP packets the source node then computes the weight value for each route.

Weight for a route $i$ is calculated based on the following:

$W i=C 1 *(R E i / \operatorname{MaxRE})+C 2 *(H C i / \operatorname{MaxHC})$ (1) where $|C 1|+|C 2|=1$.

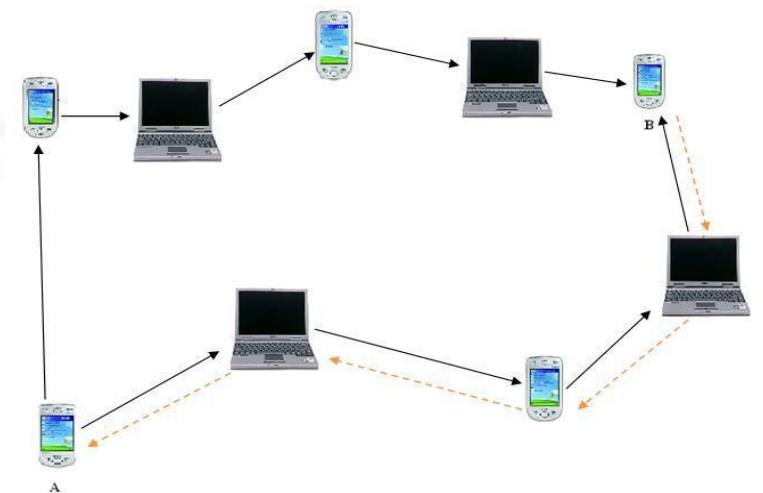

Fig 1: RREQ \& RREP Messages in MANET using AODV

\section{PERFORMANCE METRICES}

The following performance metrics are used to evaluate the effect of each scheduling algorithm:

- Throughput: It is taken as the average rate of successful messages delivery over a channel for communication. The throughput is basically measured in bits per second (bit/s or bps) unit.

- Average end-to-end delay: It is generally the average time which a data packet takes to travel to destination from source in seconds. It is usually calculated by subtracting the time at which first packet was transmitted by source from the "time at which first data packet arrived to the destination".

- Normalized Routing Load: It is defined as the total number of routing packet transmitted per data packet.

\section{Results and Discussion}

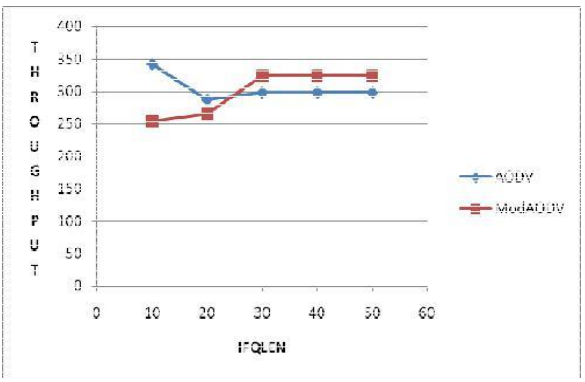

Fig 1. Throughput of modified AODV and original AODV with CBR Traffic

From Fig. 1, it is clear that throughput of modified AODV increases with increase in the number of packets in the interface queue compared to original AODV. The experiment was conducted with 11 nodes and the maximum speed was $V m=5 \mathrm{~m} / \mathrm{s}$. The Interface Queue Length was varied from 10 to 50 packets.

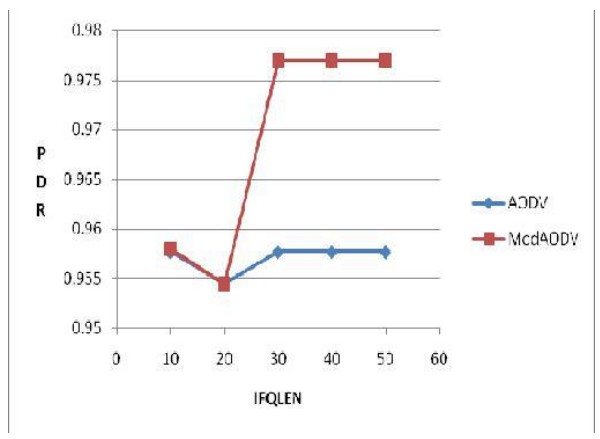

Fig 2. Packet Delivery Ratio of modified AODV and original AODV

Fig. 2 shows that packet delivery ratio of modified AODV increases with increase in the number of packets in the interface queue compared to original AODV. The number of nodes was increased to 15 and maximum speed was $V m=5 \mathrm{~m} / \mathrm{s}$.

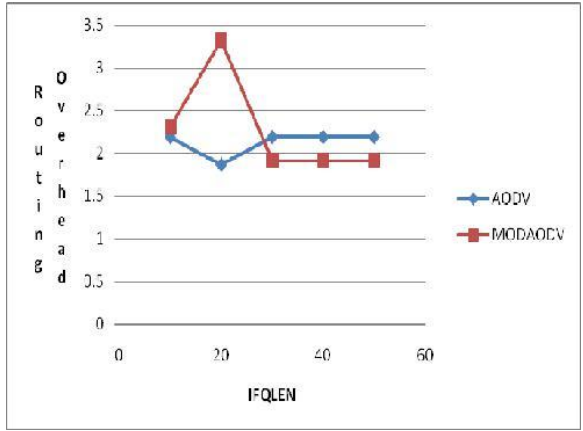

Fig 3. Routing Overhead of modified AODV and original AODV

Fig. 3 exhibits that routing overhead of modified AODV is very high with lesser number of packets in the interface queue, but gradually decreases with increase in IFQLEN. But routing overhead increases with increase in the number of packets incase of original AODV. The number of nodes used was 15 and maximum speed was $V m=5 \mathrm{~m} / \mathrm{s}$.

Table 1: Performance Comparison of Various Protocols on 10 Nodes

\begin{tabular}{|c|c|c|c|c|}
\hline $\begin{array}{c}\text { Name of } \\
\text { protocol }\end{array}$ & PDR & E2EDELAY(ms) & Throughput(kbps) & $\begin{array}{c}\text { Normalized } \\
\text { Routing } \\
\text { Load }\end{array}$ \\
\hline DSDV & 98.98 & 34.89 & 377.67 & .070 \\
\hline DSR & 99.15 & 34.75 & 387.03 & 0.026 \\
\hline AODV & 99.17 & 34.71 & 398.60 & 0.021 \\
\hline NAODV & 99.21 & 34.70 & 399.58 & 0.002 \\
\hline
\end{tabular}

Table 2: Performance Comparison of Various Protocols on 20 Nodes

\begin{tabular}{|l|l|l|l|l|}
\hline $\begin{array}{l}\text { Name of } \\
\text { protocol }\end{array}$ & PDR & E2EDELAY & Throughput & $\begin{array}{l}\text { Normalized } \\
\text { Routing } \\
\text { Load }\end{array}$ \\
\hline DSDV & 99.08 & 34.75 & 378.06 & 0.114 \\
\hline DSR & 99.15 & 34.71 & 385.34 & 0.065 \\
\hline AODV & 99.14 & 34.664 & 398.71 & 0.049 \\
\hline NAODV & 99.18 & 34.653 & 399.36 & 0.002 \\
\hline
\end{tabular}


Table 3: Comparison of Various Protocols on 30 Nodes

\begin{tabular}{|l|l|l|l|l|}
\hline $\begin{array}{l}\text { Name of } \\
\text { protocol }\end{array}$ & PDR & E2EDELAY & Throughput & $\begin{array}{l}\text { Normalized } \\
\text { Routing Load }\end{array}$ \\
\hline DSDV & 98.48 & 34.9 & 380.31 & 0.242 \\
\hline DSR & 99.04 & 34.8 & 383.41 & 0.075 \\
\hline AODV & 98.97 & 34.6 & 399.21 & 0.106 \\
\hline NAODV & 99.07 & 34.5 & 399.35 & 0.004 \\
\hline
\end{tabular}

Table 4: Comparison of Various Protocols on 40 Nodes

\begin{tabular}{|l|l|l|l|l|}
\hline $\begin{array}{l}\text { Name of } \\
\text { protocol }\end{array}$ & PDR & E2EDELAY & Throughput & $\begin{array}{l}\text { Normalized } \\
\text { Routing } \\
\text { Load }\end{array}$ \\
\hline DSDV & 98.54 & 34.76 & 384.12 & 0.310 \\
\hline DSR & 99.15 & 34.72 & 384.83 & 0.103 \\
\hline AODV & 99.17 & 34.72 & 396.78 & 0.103 \\
\hline NAODV & 99.63 & 26.18 & 422.25 & 0.009 \\
\hline
\end{tabular}

\section{CONCLUSION}

An Ad hoc on demand Distance Vector (AODV) routing protocol is modified using NS2.34 as the simulation tool. The modified AODV is evaluated through several experiments and simulations that measured the throughput, packet delivery ratio, and overhead of our network. The results are depicted in Figs. 1, 2 and 3. In this paper, Description is given about the importance of QoS ( in terms of average end to end delay and packet delivery ratio) routing in Mobile Ad-Hoc networks, challenges came across, and the approach taken. When this traffic is becomes high on the network, not all the taken routes that are found by an AODV routing protocol have enough free data rate to send packets ensuring the low end to end delay of each packets. As result, an E-AODV protocol works very well and shows its effects when the traffic on the network is comparatively high. People work in the area of an ad-hoc networks with the aim of improving the QOS to reduced the average end to end delay and enhanced the packet delivery ratio for an ad hoc networks can get benefits from this EAODV protocol. In the further work other additional network parameter will be considered.

\section{ACKNOWLEDGMENTS}

I would like to express my deepest gratitude to my Guide Prof. (Dr.) Bhawna Malik Dean Academic \& HOD and asstt. Proff. Mr. Raj Kumar Singh Rathor (M.Tech. Cocoordinator) for his guidance and support. I would also like to thank Mr.Sanjay Kumar for devoting his time in discussing ideas with me and giving his invaluable feedback.

\section{REFERENCES}

[1] N. Wang, Y. Huang and J. Chen, "A stable weight-based on- demand routing protocol for mobile ad hoc networks" Information Sciences 177(2007), pp. 5522$5537,2007$.

[2] Charles E. Perkins, "Ad Hoc Networking", Addison
Wesley, USA, 2001.

[3] David B. Johnson, Davis A. Maltz, "The Dynamic Source Routing Protocol for Mobile Ad hoc Networks", Internet Draft, draft-ietf-manet-dsr-03.txt, Oct. 1999.

[4] H. Hassanein, and A. Zhou, "Load-aware Destinationcontrolled Routing for MANETs", Elsevier Computer Communications, pp. 1551-1559, 26(2003).

[5] G. Chakrabarti, and S. Kulkarni, "Load Balancing and Resource Reservation in Mobile Ad hoc networks", Elsevier Ad Hoc Networks, accepted 14 April, 2004.

[6] S. Ahn, Y. Lim and J. Choe, "A Load-Balancing Approach in Ad-Hoc Networks", ICOIN 2003, LNCS 2662, pp. 672-681, 2003.

[7] J-H. Song, V. Wong, and V. C. M. Leung, "Load-Aware On-Demand Routing (LAOR) Protocol for Mobile Ad hoc Networks", The 57th IEEE Semiannual Vehicular Technology Conference, pp. 3:1753-1757, 2003.

[8] Yu-Chee Tseng, Wen-Hua Liao, Shih-Lin Wu, "Mobile Ad Hoc Networks and Routing Protocols", Handbook of Wireless Networks and Mobile Computing, Edited by Ivan Stojmenovic' Copyright (02002 John Wiley \& Sons, Inc. ISBNs: 0-471- 41902-8 (Paper); 0-471- 22456-1 (Electronic).

[9] Srdjan Krco and Marina Dupcinov, "Improved Neighbor Detection Algorithm for AODV Routing Protocol”, IEEE Communications Letters, vol. 7, No.12, December 2003.

[10] Venugopalan Ramasubramanian and Daniel Mossee "BRA: A Bidirectional Routing Abstraction for Asymmetric Mobile Ad Hoc Networks", IEEE/ACM Transactions on Networking, Vol 16, No.1,February 2008.

[11] Hua Qu, Peng Zhang, Ji-Hong Zhao, "A New Local Repair Scheme Based on Link Breaks for Mobile Ad Hoc Networks", 2009 Seventh Annual Communications Networks and Services Research Conference

[12] "Network Simulator, ns-2," available online at http://www.isi.edu/nsnam/ns/.

[13] Perkins C and E. Royer, "Ad-hoc on-demand distance vector routing," in Proceedings of Second IEEE Workshop on Mobile Computing Systems and Applications, February1999, pp.90-100.

[14] Boukerche A, "Performance Comparison and Analysis of Ad hoc Routing Algorithms," In Proc.of IEEEICPCC, 2001, pp.171- 178

[15] Perkins C, E. Belding-Royer, and S. Das, "Ad hoc ondemand distance vector (AODV) routing,'IETFRFC3561, July2003.

[16] Doyle S L. Doyle, A. Kokaram, T. Forde. "Ad-hoc n etworking, randommarkov fields and decision making". IEEE Signal Processing Magazine, 2006 